\title{
New Material of Sinopterus (Pterosauria, Tapejaridae) from the Early Cretaceous Jehol Biota of China
}

\author{
XINJUN ZHANG ${ }^{1,2,3}$, SHUNXING JIANG ${ }^{1,2}$, XIN CHENG $^{1,4}$ and XIAOLIN WANG ${ }^{1,2,3}$ \\ ${ }^{1}$ Key Laboratory of Vertebrate Evolution and Human Origins, Institute of Vertebrate Paleontology and Paleoanthropology, \\ Chinese Academy of Sciences (CAS), Beijing 100044, China \\ ${ }^{2}$ CAS Center for Excellence in Life and Paleoenvironment, 142 Xizhimenwai Street, Xicheng District, P O Box 643, Beijing \\ 100044, China \\ ${ }^{3}$ University of Chinese Academy of Sciences, Yuquan Road, Shijingshan District, Beijing 100049, China \\ ${ }^{4}$ Laboratório de Paleontologia, Universidade Regional do Cariri, Rua Coronel \\ Antônio Luís, 1161, Pimenta, 63195-000 Crato, CE, Brazil \\ Manuscript received on July 24, 2018; accepted for publication on January 28, 2019
}

\begin{abstract}
How to cite: ZHANG X, JIANG S, CHENG X AND WANG X. 2019. New Material of Sinopterus (Pterosauria, Tapejaridae) from the Early Cretaceous Jehol Biota of China. An Acad Bras Cienc 91: e20180756. DOI 10.1590/00013765201920180756 .
\end{abstract}

\begin{abstract}
Tapejaridae is a clade of toothless pterosaurs typically characterized by a large nasoantorbital fenestra and a premaxillary crest that extends from the anterior to the posterior part of the skull. Sinopterus dongi was the first reported Chinese tapejarid. Another genus "Huaxiapterus" was described, but it was later on determined that "Huaxiapterus" is in fact an invalid name. Here, we report on a new juvenile specimen of Sinopterus atavismus from the Jiufotang Formation of western Liaoning, China, and revise the diagnosis of this species. Sinopterus atavismus does not present a square-like crest. Moreover the feature that groove in the ventral part of the second or third phalanx of manual digit IV is not diagnostic of the species. In the new material, the skull preserves a pointed process in the middle part of the dorsal margin of the premaxillary crest, which is different from other Chinese tapejarids. Considering the new specimen is known from a large skeleton that differed from the holotype, this difference may be related to ontogeny, as the premaxillary crest of the holotype is short and does not extend as long as that of the new specimen.
\end{abstract}

Key words: Sinopterus atavismus, ontogeny, Jiufotang Formation, Liaoning, China.

\section{INTRODUCTION}

The Jehol Biota, which comprises the Yixian and Jiufotang formations, has offered a large number of pterosaur materials ( $\mathrm{Wu}$ et al. 2017). One of the pterosaur groups known from the Jehol

Correspondence to: Xiaoling Wang

E-mail: wangxiaolin@ivpp.ac.cn

ORCid: orcid.org/0000-0003-2205-2103

* Contribution to the centenary of the Brazilian Academy of Sciences.
Biota is the Tapejaridae. Based on Tupuxuara longicristatus and Tapejara wellnhoferi (type species), the Tapejaridae was established with the diagnosis of being toothless pterosaurs, supported by five synapomorphies: (1) comparatively large nasoantorbital fenestra, forming more than 45 percent of the skull length; (2) long median crest mostly formed by the premaxilla, arising from the rostral tip of the skull and extending posteriorly; (3) thin subvertical lacrimal process of the jugal; (4) 
small reversed pear-shaped orbit; and (5) a broad and well-developed tubercle at the ventroposterior margin of the coracoid (Kellner 2004, Kellner and Campos 2007, Pinheiro et al. 2011, Aires et al. 2013). Sinopterus can be assigned to the Tapejaridae by the rostral end bent downwards, the anterior part of the premaxillary sagittal crest low and orbit below the level of the upper margin of the nasoantorbital fenestra, most similar to that of Tapejara and Tupandactylus (Kellner and Campos 2007, Pinheiro et al. 2011, Andres et al. 2014). To this day, there are nine described tapejarid specimens from China (Wang and Zhou 2003, Li et al. 2003, Lü and Yuan 2005, Lü et al. 2006a, b, 2007, 2016, Liu et al. 2014). All those specimens were collected from the Jiufotang Formation. Although the diversity of Chinese tapejarids is not richer than that of Brazil, Chinese materials are still numerous and very well-preserved. However, there are still some concerns about the validity of some generic and specific names of tapejarids recovered from China. First, most pterosaur researchers concluded that "Sinopterus gui" belonged to an ontogenetically younger specimen of Sinopterus dongi, an individual with a wingspan around 0.64 m (Wang and Zhou 2006, Kellner and Campos 2007, Wang and Dong 2008, Pinheiro et al. 2011, Witton 2013), because there is no notarium and the ratio of the femur and tibia (fe/ti) in "Sinopterus gui" is 0.642 , which is similar to the proportions of the holotype of Sinopterus dongi $(\mathrm{fe} / \mathrm{ti}=0.712)$ and not 0.49 , as originally proposed. Furthermore the skull is broken and its dorsal region is not preserved, therefore if a cranial crest indeed existed cannot be established at this time (Kellner and Campos 2007). Second, Kellner and Campos (2007) pointed out that "Huaxiapterus jii" did belong to Sinopterus and that "Huaxiapterus jii" should be renamed Sinopterus jii. Some concluded that "Huaxiapterus jii" is a synonym of Sinopterus dongi (Wang and Zhou 2006, Wang and Dong 2008, Pinheiro et al. 2011, Witton 2013, Andres et al. 2014, Wu et al. 2017). The sole difference in size of the cranial crest between "Huaxiapterus jii" and Sinopterus dongi is not taxonomically diagnostic, and the possibility that it may be caused by sexually dimorphic characteristics or ontogenetic changes cannot be ruled out (Wang et al. 2014, Manzig et al. 2014, Pinheiro and Rodrigues 2017). Given the current state of research and available data, here, we consider it a synonym of Sinopterus dongi (Wang and Zhou 2003).

Lastly, Kellner and Campos (2007) argued that the "Huaxiapterus" corollatus (Lü et al. 2006a) needed a new generic name, since the type species of "Huaxiapterus" was attributed to the genus Sinopterus. Wang and Zhou (2006), Wang and Dong (2008) and Wu et al. (2017) considered "Huaxiapterus" corollatus (Lü et al. 2006a) and "Huaxiapterus" benxiensis (Lü et al. 2007) to belong to the genus Sinopterus, but kept them as valid species. Because the diagnostic features between "Huaxiapterus" and Sinopterus are mainly in the premaxillary crest morphology, the ratios of the postcranial elements are similar between them, and based on the sexually dimorphic characteristics study of the Hamipterus (Wang et al. 2014), differences between "Huaxiapterus" and Sinopterus may be caused by sexually dimorphic characteristics, therefore, "Huaxiapterus" corollatus and "Huaxiapterus" benxiensis should be renamed respectively Sinopterus corollatus and Sinopterus benxiensis.

Here, we report on a new tapejarid specimen (IVPP V 23388) with a nearly complete skeleton discovered from Sihedang, Lingyuan, Liaoning, China. The new specimen is preserved in a graywhite shale. The lacustrine deposits in this fossil locality are within the Early Cretaceous (Aptian) Jiufotang Formation. It represents a new juvenile specimen of Sinopterus atavismus (Lü et al. 2016), which is described here. Additionally, we discuss the relationship between the new material and other tapejarid pterosaurs. 


\section{MUSEUM ABBREVIATIONS}

IVPP, Institute of Vertebrate Paleontology and Paleoanthropology, Beijing, China; BVP, Beijing Natural History Museum, Beijing, China; D, Dalian Natural History Museum, Dalian, China; GMN, Geological Museum of Nanjing, Nanjing, China; ZMNH, Zhejiang Museum of Natural History, Zhejiang, China; BXGM, Benxi Geological Museum, Benxi, China; PMOL, Paleontological Museum of Liaoning, Liaoning, China.

\section{SYSTEMATIC PALEONTOLOGY}

Pterosauria Kaup, 1834

Pterodactyloidea Plieninger, 1901

Tapejaridae Kellner, 1989

Sinopterus Wang and Zhou, 2003

Sinopterus atavismus (Lü et al. 2016).

Referred specimen. A nearly completely articulated skeleton, which is housed in the Institute of Vertebrate Paleontology and Paleoanthropology, Chinese Academy of Sciences, Beijing, China under the number IVPP V 23388 (Figs. 1-5; Tables I-III).

Locality and horizon. Sihedang, Lingyuan, Liaoning Province, China; Jiufotang Formation, late Early Cretaceous (Aptian).

Revised diagnosis. Sinopterus atavismus presents the following autapomorphy: a pointed process in the middle part of the dorsal margin of the premaxillary crest. Sinopterus atavismus can be further distinguished from other Sinopterus by the following combination of characters: rostral end of upper jaw downturned with the dorsal margin of the skull formed a slant line; the length of the mandibular symphysis about three tenths of the total mandibular length; presence of lateral pneumatic foramen in midcervicals; the ratio between the ulna and humerus 1.46; the ratio between the second wing phalanx and the first wing phalanx 0.77.

\section{DESCRIPTION AND COMPARISON}

The new material of Sinopterus atavismus (IVPP $\mathrm{V}$ 23388) preserves a nearly complete and articulated skeleton (Figs. 1-5). It is a medium sized pterodactyloid. Its wingspan is about $150 \mathrm{~cm}$.

The skull of the specimen can be observed from the right side (Fig. 3). The second phalanges of the left and right manual digits IV overlap some bones of the posterior part of the skull. Several elements were displaced during fossilization, particularly most posterior skull bones. The vertebral column preserves 7 cervicals, at least 14 dorsals, and 3 sacrals as well as at least 6 caudals. The atlas and axis are missing. The left coracoid (the humerus covers most of the distal part), the distal articulation of the right coracoid and both scapulae are preserved. The wings miss their distal parts. The pelvic girdle preserves the ilium, pubis, prepubis, and ischium. The hind limbs are well preserved, and most of the right femur is covered by other elements.

Several elements, like the scapula and coracoid, the extensor tendon process and the first wing phalanx, carpals, sacral vertebrae, pelvic girdle, fibula and tibia, tarsals, and the epiphysis of the humerus are not fused, and many pits and grooves in the distal end of the long bones suggest that this specimen represents a juvenile individual at the time of death (Bennett 1993, Kellner 2015). Except Sinopterus dongi (D 2525, Lü et al. 2006b), all other described Chinese tapejarid specimens (Wang and Zhou 2003, Li et al. 2003, Lü and Yuan 2005, Lü et al. 2006a, 2007, 2016, Liu et al. 2014) were juvenile individuals at the time of death.

SKULL

The jaws are edentulous, a typical feature of the Tapejaridae (Kellner 2004, Kellner and Campos 2007, Pinheiro et al. 2011, Aires et al. 2013). The nasoantorbital fenestra is large and elliptic in shape, also a common feature in tapejarids (Wellnhofer 


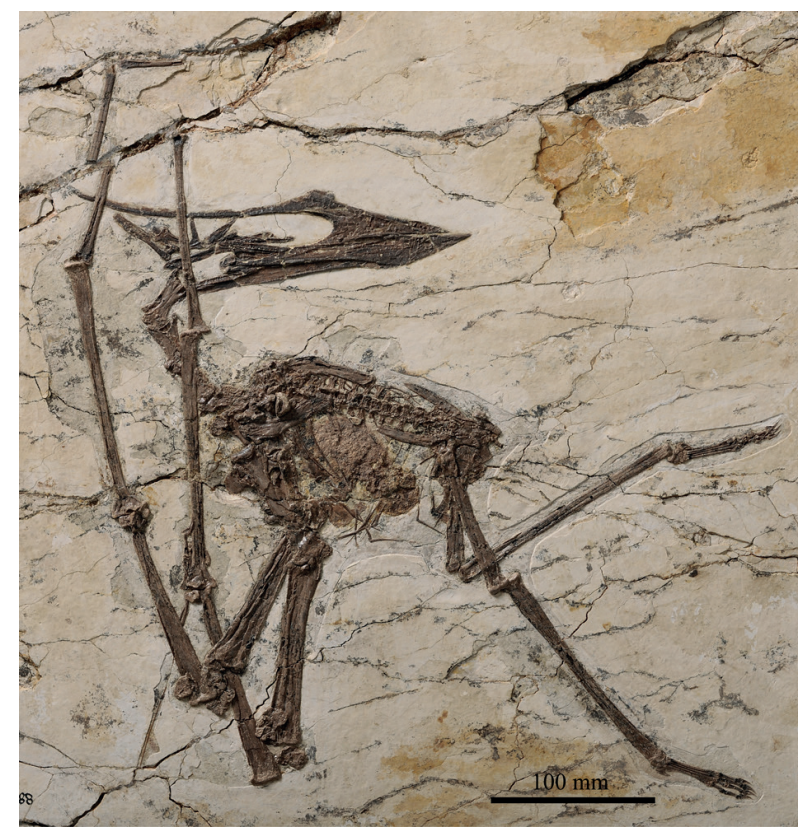

Figure 1 - The skeleton of Sinopterus atavismus IVPP V 23388.

TABLE I

Measurements of the cranium of Sinopterus atavismus (IVPP V 23388) (in mm).

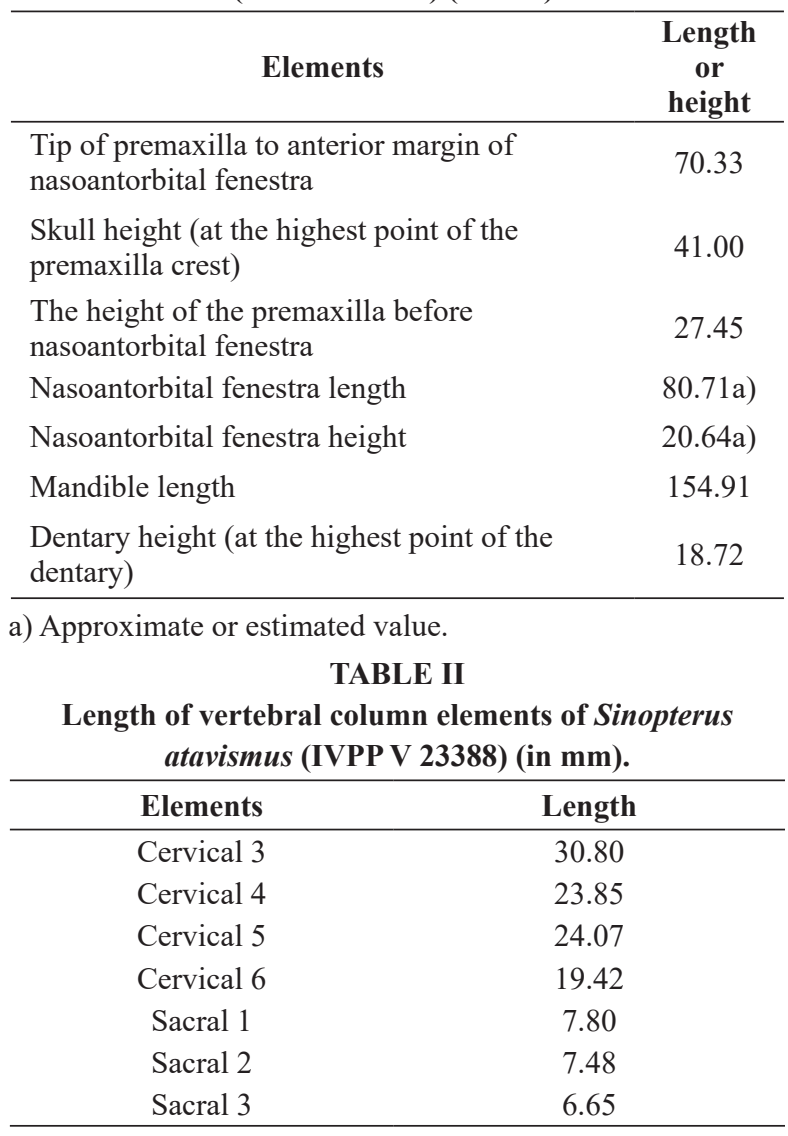

and Kellner 1991). As the length from the ventral part of quadrates to the skull roof is incomplete, we chose to measure the height of the rostrum (table I). Besides, the rostral value ( $\mathrm{RV}=$ ros- $1 /$ aen- $\mathrm{h}$ ) is an index for measuring the elongation of the rostrum. The ros-1 is measured from the anteriormost point of the external naris to the tip of the premaxillae and aen-h is measured perpendicularly from the ventral margin of the skull excluding the premaxillary crest (Kellner 2010). The rostral value of the material is the second largest among Chinese tapejarids (Table IV), suggesting it has a lower and longer rostrum than most of those species.

\section{Premaxilla}

The premaxilla was fused with the anterior portion of the maxilla, without an obvious suture. The premaxilla forms the anterodorsal margin of the nasoantorbital fenestra; at the rostral tip, the premaxilla is elongate and sharply pointed, a common feature within the Sinopterus (Wang and Zhou 2003, Li et al. 2003, Lü and Yuan 2005, Lü et al. 2006a, b, 2007, 2016). The anterodorsal margin of the premaxilla forms a narrow premaxillary crest. The anterior part of the premaxillary crest is low and flat; it extends backwards as an elongate process beyond the posterior margin of the skull, which are the typical features that permit the classification of the new specimen IVPP V 23388 in the Sinopterus (Wang and Zhou, 2003, Li et al. 2003, Lü and Yuan 2005, Lü et al. 2006a, 2007, 2016). The dorsal margin of the premaxillary crest in its middle part has a pointed process (Fig. 3). Due to its preservation, the left skull is not fully covered by the right side, showing a square-like fragment (Fig. 3). However, the square-like bone is easily recognizable as it is not the real right premaxillary crest, as it has an apparent suture between the square-like bone and the right premaxillary crest, which is not present in other pterosaurs. The posterior extension of the premaxillary crest is 


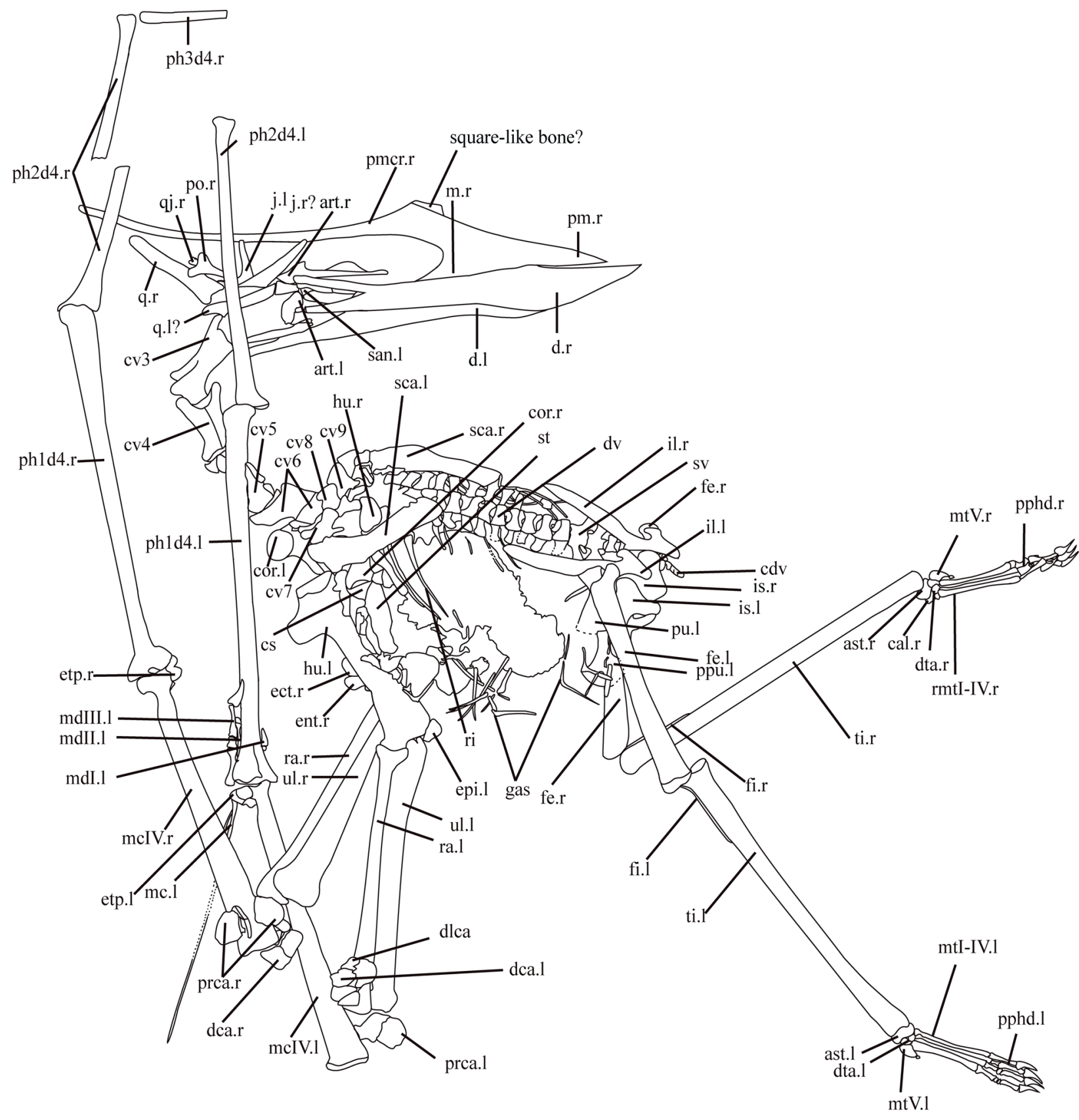

$100 \mathrm{~mm}$

Figure 2 - Line drawing of the preserved elements of Sinopterus atavismus IVPP V 23388. Abbreviations: art, articular; ast, astragalus; cal, calcaneum; sca, scapula; cdv, caudal vertebra; cor, coracoid; cv3-9, cervical vertebrae 3-9; d, dentary; dca, distal carpal; dlca, distal lateral carpal; dta, distal tarsal; dv, dorsal vertebra; ect, ectepicondyle; ent, entepicondyle; epi, epiphysis; etp, extensor tendon process; fe, femur; fi, fibula; gas, gastralia; hu, humerus; il, ilium; is, ischium; j, jugal; 1, left; m, maxilla; mc, metacarpal; mcIV, metacarpal IV; md I-III, manual digits I-III; mt I-V, metatarsal I-V; ph1d4- ph3d4, first- third phalanx of manual digit IV; pm, premaxilla; pmcr, premaxillary crest; po, postorbital; pphd1-4, phalanges of the pedal digits 1-4; ppu, prepubis; prca, proximal carpal; pu, pubis; q, quadrate; qj, quadratojugal; r, right; ra, radius; ri, rib; st, sternum; san, surangular; sv, sacral vertebra; ti, tibia; ul, ulna. 
TABLE III

Measurements of the length of postcranial bones of Sinopterus atavismus (IVPP V 23388) (in mm).

\begin{tabular}{|c|c|c|}
\hline & Left & Right \\
\hline scapula & 60.76 & $57.76^{* *}$ \\
\hline coracoid & 48.61 & $27.62 * *$ \\
\hline humerus & 79.77 & 81.01 \\
\hline ulna & 116.32 & 117.23 \\
\hline radius & 114.16 & 113.23 \\
\hline metacarpal IV & 127.49 & 125.39 \\
\hline metacarpal I & 107.92 & - \\
\hline phalanx of manual digit I 1-2 & $2.49 * *, 10.03$ &,-- \\
\hline phalanx of manual digit II 1-3 & $-, 15.06,-$ &,-- \\
\hline phalanx of manual digit III 1-4 & $16.21,4.80,14.30,11.60$ &,,,--- \\
\hline phalanx of manual digit IV 1-4 & $158.87,122.59,-,-$ & $159.93,123.89,39.15^{* *},-$ \\
\hline ilium & 64.03 & 66.62 \\
\hline femur & 97.86 & 100.97 \\
\hline tibia & 149.59 & 151.65 \\
\hline fibula & 55.45 & $45.45^{* *}$ \\
\hline metatarsal I-V & $35.36,35.61,33.58,31.20,8.77$ & $36.18,36.36,34.20,32.07,8.84$ \\
\hline phalanx of pedal digit I 1-2 & $13.09,9.85$ & $13.27,8.86$ \\
\hline phalanx of pedal digit II 1-3 & $5.17,12.29,10.27$ & $5.21,12.75,10.69$ \\
\hline phalanx of pedal digit III 1-4 & $6.27,2.31,11.16,10.24$ & $6.70,-, 12.54,10.99$ \\
\hline phalanx of pedal digit IV 1-5 & $10.80,0.99,1.12,10.41,10.41$ &,,,,,----- 11.30 \\
\hline phalanx of pedal digit $\mathrm{V}$ & 1.94 & 2.33 \\
\hline
\end{tabular}

** preserved length; — not preserved.

elongated, as in Sinopterus benxiensis (Lü et al. 2007), but several other Sinopterus specimens have their crests broken posteriorly. Posterior to the middle part, the dorsal margin of the premaxillary crest is concave in the new specimen, while in other Chinese tapejarid specimens which have this region preserved the margins are all horizontal, this is more likely related to the taphonomy since it is a fragile structure.

\section{Maxilla}

The maxilla is a slender element which constitutes the upper jaw ventral to the premaxilla and anterior and ventral to the nasoantorbital fenestra. The most part of the maxilla is covered by the right dentary. Anterior to the nasoantorbital fenestra, the maxilla shows a coarser surface. Although the posterior ramus of the maxilla cannot be observed, apparently it continues below the nasoantorbital fenestra.

\section{Postorbital}

The postorbital is triangular and participates the posteroventral margin of the orbit and the anteroventral margin of the upper temporal fenestra. The postorbital has three rami. The anterior and posterior branches both form an angle of about $145^{\circ}$ with each other. The anterior and posterior processes contact the jugal and squamosal ventrally, respectively. The anterior process is elongated.

Jugal

The left jugal is preserved and not in its original anatomic position and missing the maxillary 


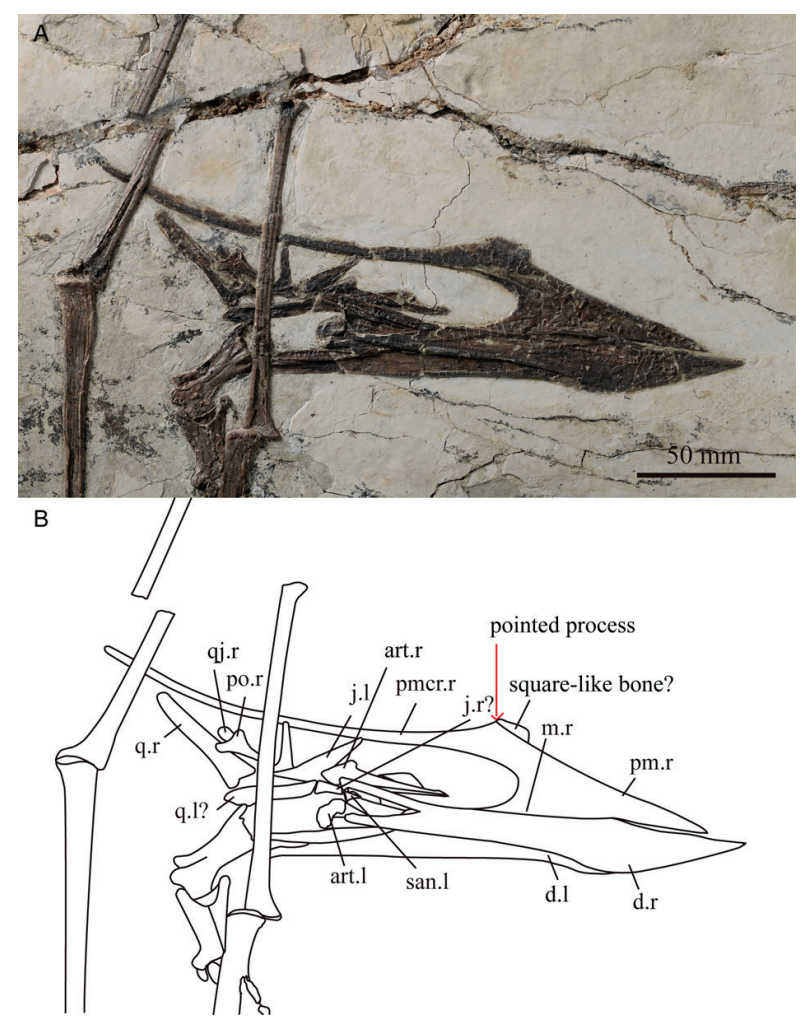

Figure 3 - Photo (a) and line drawing (b) of the skull of Sinopterus atavismus IVPP V 23388. Abbreviations: art, articular; d, dentary; j, jugal; 1, left; m, maxilla; pm, premaxilla; pmcr, premaxillary crest; po, postorbital; q, quadrate; qj, quadratojugal; r, right; san, surangular.

ramus. Due to its preservation, it cannot be easily seen whether the jugal is a triradiate element or a tetraradiate element. The jugal was fused with the quadratojugal in most other Sinopterus specimens. However, from the photographs of Sinopterus lingyuanensis, the jugal is a triradiate element (Lü et al. 2016). Therefore, we favor the jugal as a triradiate element in the new specimen. While in the common condition for Brazilian tapejarids is a tetraradiate jugal, with two posterodorsal rami bounding both the anterior and posterior margins of the infratemporal opening (Wellnhofer and Kellner 1991). This may be a significant difference between Chinese and Brazilian tapejarids. The general shape of the jugal in the new specimen is similar to those of other Chinese tapejarids, except it is thicker than them as a whole.
The maxillary ramus of the jugal is elongated and slender and forms most of the ventral margin of the nasoantorbital fenestra. The lacrimal ramus is more slender than the postorbital ramus. It is preserved in a $95^{\circ}$ angle with the postorbital ramus, forming a bony bar that separates the orbit from the nasoantorbital fenestra. Ventral to this contact, the lacrimal ramus has a lateral depression that ends ventrally in a ridge. This condition is observed in Tapejara and other pterodactyloids such as Pteranodan and anhanguerids (Kellner and Tomida 2000). The postorbital ramus is broad. It is slightly longer than the lacrimal ramus. The left postorbital ramus is in front of the left lacrimal ramus due to disarticulation.

\section{Quadratojugal}

The quadratojugal only preserves a small and thin fragment. It forms the ventral margin of the lower temporal fenestra. There is no fusion between the quadratojugal and quadrate. Since the quadratojugal is poorly preserved, it is difficult to get more information.

\section{Quadrate}

The quadrate is a relatively elongated bone. The quadrate has a straight shaft and an expanded end. Also, the distal end of the quadrate has two articular condyles, which would connect with the lower jaw. Due to its preservation, it cannot provide more details on the quadrate articulation surface.

\section{MANDIBLE}

The mandibular elements that can be recognized are the articular, surangular and dentary. The entire right dentary moved forward and up in this specimen, causing some bones of the left mandibular ramus to be exposed in medial view. The mandible is edentulous and robust; the anterior tip of the dentary is pointed. The ventral sagittal crest of the mandible tapers slightly from its high 
point toward the tip of the mandible; these features are similar to the other Sinopterus (Wang and Zhou 2003, Li et al. 2003, Lü and Yuan 2005, Lü et al. 2006a, 2007, 2016).

\section{Dentary}

The dentary constitutes the majority of the mandible. The rostral surface has a rugose texture, similar to the rugose surface of the maxilla. While in the posterior portion of the dentary, the surface changes from rugose to smooth. The mandibular symphysis bears a low bony crest that extends from the tip of the mandible to a point about three tenths from the posterior end. The dentary extends towards the caudal portion of the mandible overlying the upper portion of the surangular. Also, the dentary reaches the articular.

\section{Surangular}

The surangular forms the dorsal margin of the mandibular ramus and the upper third of the medial surface of the ramus. Most of the surangular, particularly in the anterior region, is overlain by the right dentary. The surangular is unfused with dentary and parallel to the dentary. Posteriorly, the surangular contacts the articular.

\section{Articular}

The articular is the smallest element of the lower jaw (Wang et al. 2012). The articular bears a welldeveloped retroarticular process.

\section{CERVICAL VERTEBRAE}

Cervicals 3-6 are well preserved and articulated, while the cervicals 7-9 are broken and slightly displaced. The morphology of cervicals 3-6 is very similar in being strongly procoelous, possessing an elongate, blade-like neural spine, that are higher in this specimen than that of the Chinese tapejarid specimen PMOL-AP00030
(Liu et al. 2014). The cervical 3 is about 37.86 $\mathrm{mm}$ long from the tip of the prezygapophysis to the distal end of the postexapophysis. Cervical 3 , exposed ventrolaterally, is found next to the skull, its prezygapophyses and postzygapophyses are projected anterolaterally and ventrolaterally, respectively, with the postzygapophyses more divergent. The prezygapophyses are relatively long and slender; in contrast, the postzygapophyses are stout and extended, similar to that of other Chinese tapejarids (Liu et al. 2014). The minimum width is about $9.77 \mathrm{~mm}$ at the mid-point of the cervical. Besides, it has a well-developed hypapophysis in the midline and a small lateral pneumatic foramen situated in the probable contact region of the centrum and the neural arch (Fig. 4), contrasting with the absent condition in other Chinese tapejarids (e.g. Lü et al. 2006b, Liu et al. 2014). The cervicals 4 and 5 are both exposed in dorsal view, while only half of the cervical 5 is preserved. The fourth cervical is about $30.00 \mathrm{~mm}$ in maximal length and $9.20 \mathrm{~mm}$ in minimal width. Therefore, the ratio of the length versus width is 3.3 , in similar proportion to that of another Chinese tapejarid, such as PMOL-AP00030 (3.5) (Liu et al. 2014). The anterior margin is tightly curved anteriorly with an acute angle of about $85^{\circ}$; while the left first wing phalanx covers the posterior margin, it is easy to deduce that the posterior margin is relatively gently curved posteriorly with an obtuse angle, similar to that of another Chinese tapejarine (Liu et al. 2014). Cervical 6 is preserved in lateral view. Compared to the cervicals 3-7, cervicals 8-9 are more like dorsals and well reduced in size.

\section{DORSAL VERTEBRAE}

In this specimen, at least 14 dorsal vertebrae are preserved. There are 11 dorsals found articulated. All the neural spines of the dorsals were crushed to overlap the right transverse processes. No notarium is developed and no articulation surface is present 

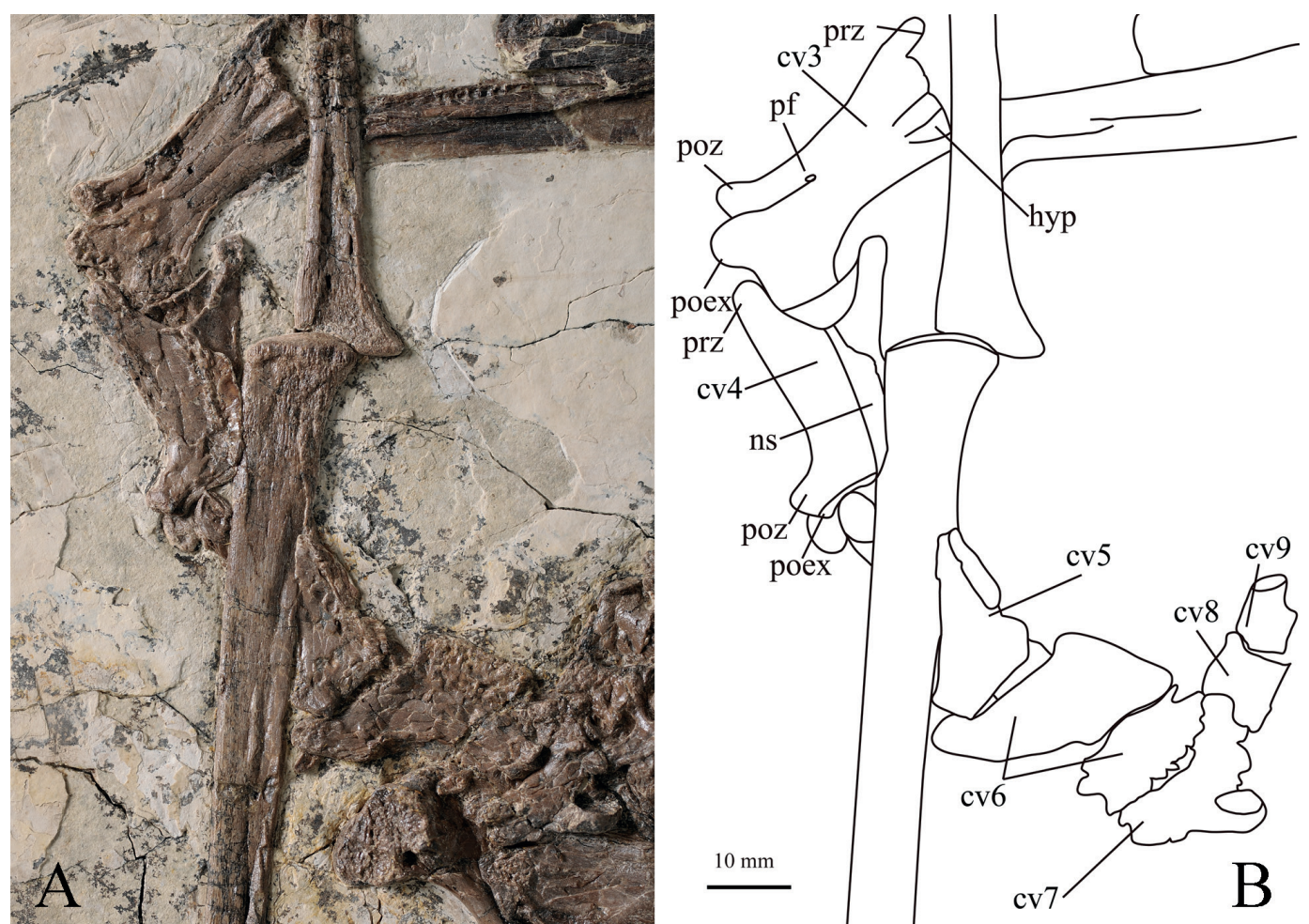

Figure 4 - Close up of cervical vertebrae 3-6 of Sinopterus atavismus, IVPP V 23388. Abbreviations: cv3-9, cervical vertebrae 3-9; hyp, hypapophysis; ns, neural spine; pf, pneumatic foramen; poex, postexapophysis; poz, postzygapophysis; prz, prezygapophysis.

for the scapula. The anterior dorsals are comparable with the last cervical in size. The transverse process is well developed with a minimal width of about $2.85 \mathrm{~mm}$. The transverse processes of the anterior dorsals are extended slightly posteriorly; while the transverse processes of the posterior dorsals that are close to the sacrals are extended slightly anteriorly. The anterior and the posterior edges of the transverse processes are both distinctly curved from the diapophysis of the transverse process narrowing to the anterolateral and posterolateral corner of the centrum where the parapophysis is raised, respectively. The neural spines are about equal height and well developed. The neural spines are about $5.28 \mathrm{~mm}$ in maximal length and $3.00 \mathrm{~mm}$ in minimal width.

\section{SACRAL VERTEBRAE}

The sacrum is preserved in IVPP V 23388, with three articulated sacral vertebrae, associated with the ilia and exposed from the dorsal side. There is no fusion between the sacrals and none of the sacrals fuse into a synsacrum. The first three sacrals show intercostal fenestrae. The neural spines are low along the midline of the neural arches. The transverse process of the sacral vertebrae points posterolaterally. The size of the sacral vertebrae gradually decreases posteriorly. Since the posterior end of the sacrals are covered by pelvic bones, it is not clear how many of them are there in total.

\section{CAUDAL VERTEBRAE}

In IVPP V 23388, five caudals are preserved in ventrolateral view. In any case, there was surely at least one more caudal vertebra posterior to the last preserved one since the tail lacks the distal part. Each vertebra is short, with a total length of 12.09 $\mathrm{mm}$, probably indicating a short tail. The centrum is smooth and procoelous. The size of the centrum 
varies, with the posterior three smaller than the anterior two.

\section{RIBS AND GASTRALIA}

At least 9 ribs are preserved from the left side. The three best-preserved ribs are covered by the scapula. The remaining ribs are incomplete. The length of the ribs on both sides gradually increases toward the middle. Their shafts are sub-parallel, arched dorsally and slightly curved distally, ending in a slightly sharped distal end.

Besides, several gastralia are observable, and they drifted away and are clearly displaced from their original anatomical position; four of them are a wide "V"-shape.

\section{STERNUM}

The sternum of IVPP V 23388 is incomplete. The preserved parts include the cristospine and part of the sternal plate, which are preserved in dorsal view. The plate is a broad, thin, and flattened bone that has a depression in the middle and an edge with some articulations to posterior sternal ribs. The cristospine is $8.05 \mathrm{~mm}$ long. The shape of the cristospine is a short triangle, tapers gradually toward its anterior end, and whose articulations with the coracoids are asymmetric. The anterior portion of the sternum is relatively stout and thick; while the posterior portion of the bone is thinner and more flat.

\section{CORACOID}

The left coracoid is exposed in lateral view. The coracoid is straight, robust and has a more expanded proximal end with a coracoidal glenoidal cavity (Fig. 5), as reported in Tapejara wellnhoferi (Eck et al. 2011). The left coracoid is about $80 \%$ of the scapula in length (Table III). The distal end of the coracoids articulates in a dorsoventral orientation with the convex lateral surface of the base of the cristospine. The articulation with the sternum is obviously concave. The glenoid part of the coracoid is expanded. Since some cervicals cover the posteroventral portion of the left coracoid, it is not possible to recognize the presence of a fan-like flange.

\section{SCAPULA}

The left scapula is preserved in dorsal view, and the right one is incomplete. The scapula is a long, bladelike element, approximately 4.8 times as long as it is wide, similar to that of Tapejara wellnhoferi (Eck et al. 2011). The scapula is curved medially from its proximal portion that sets in an angle of about $145^{\circ}$ with the scapular shaft. The scapula is longer than the coracoid (Table III), the usual condition in most pterosaurs (Kellner and Moody 2003). The proximal third of the scapula is expanded, forming the scapular body and the articular surface with the coracoid; while the remainder of the bone is relatively constant in width (Fig. 5). The scapular process is placed above the glenoid, and the glenoid is robust and well developed (Aires et al. 2013).

\section{HUMERUS}

Both humeri are displaced from the glenoid fossae. The left humerus is well exposed in dorsal view. The right humerus is poorly exposed in ventral view as the overlay of other elements partially obscures the shaft.

The humerus is stout, with a saddle-shaped head and prominent deltopectoral crest. The deltopectoral crest is long and straight, occupying about $20 \%$ the length of the shaft of the humerus. The distal margin of the deltopectoral crest is round. The distal margin is curved more gently than the proximal margin and they are almost parallel to each other.The long axis of the deltopectoral crest and the long axis of the humerus form an angle of approximately 90 degrees. Proximally, there are no pneumatic foramina present on the dorsal side of the humerus, as in another Chinese tapejarine (Liu 


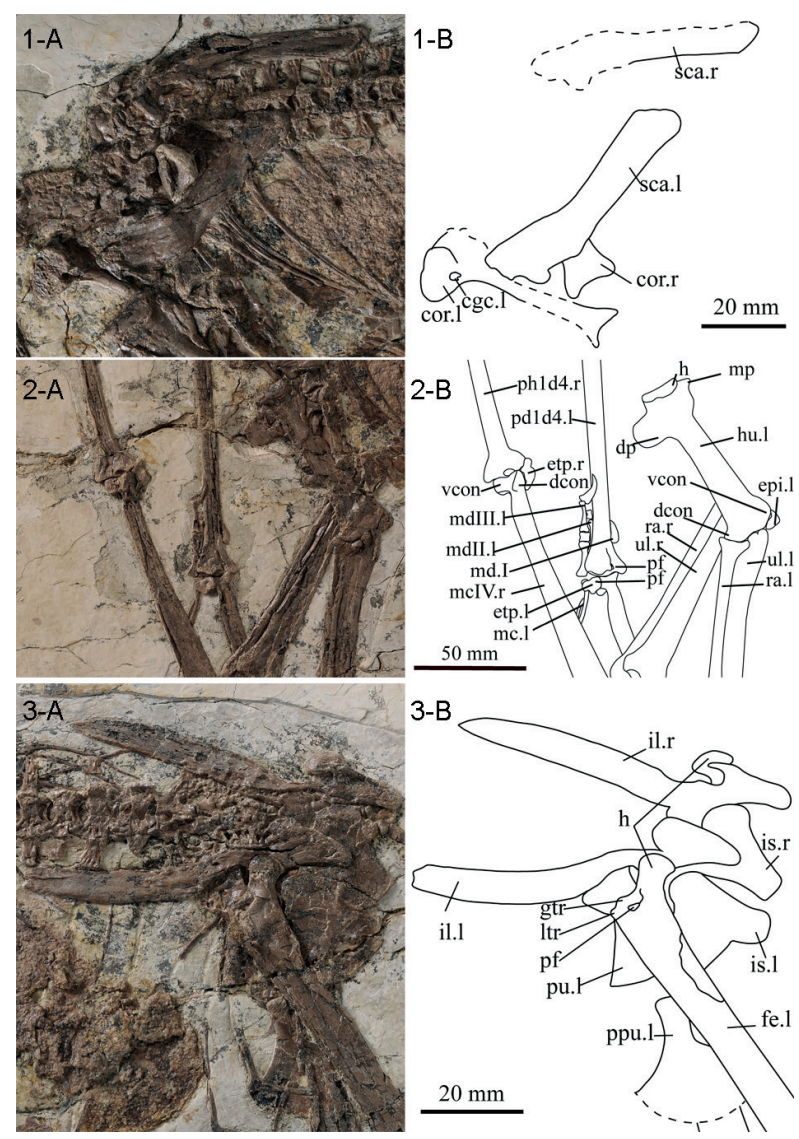

Figure 5 - Sinopterus atavismus, IVPP V 23388. Plate 1. Pectoral girdle. Plate 2. Humerus, ulna, radius, manual Digits I-III, wing metacarpal and wing finger. Plate 3. Pelvic girdle and femur. Abbreviations: cgc, coracoidal glenoidal cavity; cor, coracoid; dcon, dorsal condyle; dp, deltopectoral crest; epi, epiphysis; etp, extensor tendon process; fe, femur; gtr, greater trochanter; h, head; hu, humerus; il, ilium; is, ischium; ltr, lateral trochanter; 1, left; mc, metacarpal; mcIV, metacarpal IV; md I-III, manual Digits I-III; mp, medial process; pf, pneumatic foramen; ph1d4, first phalanx of manual digit IV; ppu, prepubis; pu, pubis; r, right; ra, radius; sca, scapula; ul, ulna; vcon, ventral condyle.

et al. 2014); however, a pneumatic foramen was reported on the dorsal side in Tapejara (Eck et al. 2011). The shaft of the humerus is straight, similar to that of most Chinese tapejarids (e.g., Wang and Zhou 2003, Lü and Yuan 2005, Lü et al. 2016), while in some Chinese tapejarids it is slightly curved anteriorly (e.g. Lü et al. 2006, Liu et al. 2014). The shape of the distal end of the humerus is slightly expanded and forms the articular surface for the radius and ulna. Near the distal end of the humerus, there is a small irregular bone which possibly represents the unfused humeral epiphysis (Fig. 5), as that in Pteranodon (Bennett 2001). A similar condition was reported in the other Chinese tapejarids (Lü and Yuan 2005, Liu et al. 2014), implying an immature condition. On the ventral surface of the right humeral epiphysis, there is a large ectepicondyle and small entepicondyle.

\section{RADIUS AND ULNA}

The left ulna and radius are well exposed in dorsal view, and the carpals partially cover their distal ends. The right ulna and radius are well exposed in lateral view except for their proximal part that is partially obscured by the overlying sternum and left humerus.

The ulna has a straight shaft and expanded ends. Although the proximal portion is slightly damaged, the trochlear cotyles are clearly to observe. The radius is about the same length as the ulna. The width of the ulna is about twice the radius. Parallel to the ulna, the radius is relatively slender. Proximally, the radius is expanded with a convex anterior side. Distally, the ulna and radius have lots of dots, implying an immature individual (Bennett 1993, Kellner 2015). Both of them are straight and much longer than the humerus (Table III). The radius, wing metacarpal and the first phalanx of the wing digit are 1.5, 1.6 and 2 times the length of the humerus, respectively (Table III).

\section{CARPUS}

The carpals are all unfused and displaced from their original position. The left carpal is complete, whose proximal series consists of two carpals, four in the distal series and the lateral distal carpal (preaxial carpal). The proximal carpals are slightly smaller than the distal carpals. The carpal elements are typically sub-rectangular in shape. There are at least two irregular pneumatic foramina on the 
left side of the proximal carpals, as in Pteranodon (Bennett 2001). The right side only exposes four elements. No pteroid or sesamoids were identified.

\section{METACARPUS}

Both wing metacarpals are preserved and they are straight, robust and long. The left-wing metacarpal is exposed in dorsal view, and the right-wing metacarpal in ventral view. The wing metacarpal is slightly expanded at the proximal end. The distal end has two condyles for articulation with the first wing phalanx. The articular surface of the ventral condyle is rounded at the end, while the dorsal condyle is wider than the ventral condyle, as that in Tapejara (Eck et al. 2011). A medially directed tubercle is observed on the anterodorsal margin of the proximal face of the wing metacarpal. There are no pneumatic foramina present on its posterior face between the distal condyles, which has been reported in Tapejara (Eck et al. 2011). The metacarpal IV is approximately 1.1 of the ulna length and shorter than the first phalanx of the wing digit (Table III), a proportion similar to that of other Chinese tapejarids (Wang and Zhou 2003, Li et al. 2003, Lü and Yuan 2005, Lü et al. 2006a, b, 2007, 2016). Besides, the left side preserves two other slender, elongated metacarpals. They are all incomplete. The longer one is the metacarpal I, and the shorter one may be the metacarpal II. The metacarpal I is slightly shorter than the wing metacarpal (Table III).

\section{MANUAL DIGITS I-III}

Digit I is the shortest and digit III is the longest. Despite the poor preservation of the digits of the specimen, digits I-III appear to have the typical phalangeal count for pterosaurs: 2, 3, 4. The preserved phalanges are slender with expanded proximal and distal ends and concave and convex articular faces respectively, same as Tapejara (Eck et al. 2011). Digits I and III end in large, robust, strong curved and pointed unguals, but the claw of digit II is missing. The first and the third phalanges of digit III are about the same length, but the second phalange of digit III is quite short, as that in other Sinopterus (e.g., Sinopterus dongi IVPP V 13363; Sinopterus dongi D 2525; Sinopterus lingyuanensis) (Wang and Zhou 2003, Lü et al. 2006b, 2016). A deep groove is present on the dorsal surface of the unguals.

\section{WING FINGER (MANUAL DIGIT IV)}

According to the ratios of the wing phalanges (WP) of Sinopterus dongi (Wang and Zhou 2003), we estimate the total length of the wingspan is about 1.5 meters. From the first wing phalanx to the third wing phalanx, the length of the shaft gradually decreases distally (Table III). The first phalanx of the wing finger is a straight, elongate element. The proximal articular surface is expanded relative to the shaft. The proximal part of wing phalanx 1 has a pneumatic foramen on its dorsal surface (Fig. 5). The distal end of the same phalange is markedly expanded and had a broad contact with the concave articular facet of the proximal end of the second wing phalanx (Lü et al. 2006b). The proximal articulation of the left first wing phalanx has an unfused extensor tendon process. The extensor tendon process has a broad base and two expanded regions on the top, with the largest directed caudally and the smallest directed cranially, a similar condition as the Anhanguera piscator (Kellner and Tomida 2000). A small, round pneumatic foramen is present on the ventral surface of the extensor tendon process (Fig. 5), a similar condition to Pteranodon (Bennett 2001). The second phalanx is a straight element and is expanded at the proximal and distal margins, forming the articular surfaces. The third phalanx is preserved only as a fragment including the proximal articular surface. However, the ventral margins of the second and third phalanges of manual digit IV preserve poor, 
TABLE IV

Measurements of the skull of Tapejaridae specimens from the Jiufotang Formation in western Liaoning of China (in mm).

\begin{tabular}{|c|c|c|c|c|c|c|c|c|}
\hline & $\begin{array}{c}S . \\
\text { dongi }\end{array}$ & "S. gui" & $\begin{array}{c}S . \\
\text { lingyuanensis }\end{array}$ & "H. jiï" & $\begin{array}{c}\text { "H". } \\
\text { corollatus }\end{array}$ & $\begin{array}{c}\text { "H". } \\
\text { benxiensis }\end{array}$ & $\begin{array}{c}\text { "H". } \\
\text { atavismus }\end{array}$ & $\begin{array}{c}\text { Sinopterus } \\
\text { atavismus } \\
\text { IVPP } \\
\text { V } 23388 \\
\end{array}$ \\
\hline A & 170 & 85 & 134.5 & $138 * *$ & $128 * *$ & 232 & 87.4 & 225.25 \\
\hline B & 48 & 24 & 40.5 & 50.9 & 56 & 64 & 35.3 & 70.33 \\
\hline $\mathrm{C}$ & 27.37 & 10 & 13.5 & 40 & 40 & 44.8 & 12.2 & 27.45 \\
\hline D & 25 & 9 & 10 & 29 & 26 & 32 & 11.8 & 20.97 \\
\hline $\mathrm{A} / \mathrm{C}$ & 6.21 & 8.5 & 9.96 & - & - & 5.80 & 7.16 & 8.20 \\
\hline $\mathrm{B} / \mathrm{D}(\mathrm{RV})$ & 1.92 & 2.67 & 4.05 & 1.76 & 2.15 & 2.00 & 3.00 & 3.35 \\
\hline
\end{tabular}

Measurements of Sinopterus dongi IVPP V 13363 from Wang and Zhou (2003), "Sinopters gui” BVP 077 from Li et al. (2003), Sinopterus lingyuanensis from Lü et al. (2016), "Huaxiapterus jii" GMN-03-11-001 from Lü and Yuan (2005), "Huaxiapterus" corollatus ZMNH M 8131 from Lü et al. (2006a), "Huaxiapterus" benxiensis BXGM V 0011 from Lü et al. (2007), "Huaxiapterus" atavismus from Lü et al. (2016). Abbreviations: S. dongi = Sinopterus dongi IVPP V 13363; "S. gui” = Sinopterus dongi BVP 077 ("Sinopters gui" BVP 077); S. lingyuanensis = Sinopterus lingyuanensis; "H”. jii = Sinopterus dongi GMN-03-11-001 (“Huaxiapterus jii” GMN-03-11-001); "H”. corollatus = Sinopterus corollatus ZMNH M 8131 ("Huaxiapterus" corollatus); "H”. benxiensis= Sinopterus benxiensis BXGM V 0011 ("Huaxiapterus" benxiensis); " $H$ ”. atavismus = Sinopterus atavismus ("Huaxiapterus" atavismus). A= Tip of premaxilla- end of the premaxilla crest; $\mathrm{B}=\mathrm{Rostral}$; $\mathrm{C}=$ The height of the premaxilla before nasoantorbital fenestra (including the premaxillary crest); $\mathrm{D}=$ The height of the premaxilla before nasoantorbital fenestra (excluding the premaxillary crest); RV, rostral value (Kellner 2010). ** preserved length; — not preserved.

and we cannot tell whether these ventral margins of the elements have grooves or not.

\section{ILIUM}

The ilium, pubis and ischium formed a closed acetabular cavity. Both ilia are preserved in the new specimen. The left ilium is exposed in lateral view and the right side in medial view. The ilium has a long preacetabular process, forming more than two thirds of the total length of the bone, preserved as an elongate, compressed blade. The medial and lateral margins of the ilium form a slightly concave arc; an oval depression on the medial margin of the bone, immediately posterior to the iliac process, represents the dorsal half of the acetabulum, similar to Tapejara (Eck et al. 2011). It has a straight medial margin and a gently rounded lateral margin, as in Pteranodon (Bennett 2001).

PUBIS

Only the left pubis is preserved. The preservation is poor and only exposed the distal part. The preserved part indicates the pubis forms the anteroventral part of the acetabulum and articulates with the proximal part of the prepubis. The ventral and posterior margins of the bone are convex.

\section{ISCHIUM}

Only the left ischium is exposed. The ischium is a thin, sub-triangular shaped plate of bone that forms the posteroventral part of the acetabulum. In lateral view, the caudal margin is slightly curved, starting very thick and rounded and becoming thinner until it reaches a distal projection that is directed outward. The pubis contacts the ilium dorsally, and the ischium posteriorly.

\section{PREPUBIS}

The proximal part of the prepubis is rod-like, and the distal part is fan-like. The proximal articular surface with the pubis is narrow, but the bone expands mediolaterally approaching its anterior margin, similar to the condition in Tapejara (Eck et al. 2011). 
FEMUR

The femur is straight and slender. It has a distinct head set apart from the shaft by a narrow neck. The neck is well preserved and angled anteromedially. The shape of the head is hemispherical. Lateral to the femoral neck is a well-developed greater trochanter (Fig. 5). Between the greater trochanter and femoral neck is a pneumatic foramen. The distal articulation is formed by two condyles, which are separated by a shallow intercondylar sulcus. The lateral condyle is larger than the medial, as that in Anhanguera piscator (Kellner and Tomida 2000), contrary to the condition observed in Pteranodon (Bennett 2001).

\section{TIBIA AND FIBULA}

The tibia is long and straight. According to the measurements, the femur/tibia ratio is about 0.7. Other Chinese tapejarids varied between 0.6 and 0.7 , whether big or small, which might suggest that the ratio of the femur/tibia in this genus changes little. The proximal articulation of the tibia is oval and smooth. The thickness of the tibia varies little from proximal part to distal end, different from Tapejara (Eck et al. 2011), whose shaft tapers towards the distal termination.

The fibula does not reach the tarsus, is reduced and less than 2/5 the length of the tibia (Table III). The tibia forms majority of the proximal articular surface with the femur. The fibular caput contacts the tibia $1.96 \mathrm{~mm}$ distal to the proximal articulation.

\section{TARSUS}

All tarsal elements of this specimen, including the proximal tarsal series (astragalus and calcaneum), are unfused. The right tarsus consists of two proximal tarsals, the astragalus and calcaneum and three distal tarsals in ventral view. The left tarsus only exposed the astragalus and two distal tarsals in dorsal view. The astragalus is the largest tarsal bone. The astragalus is sub-rectangular with rounded edges. Its dorsal margin is weakly concave. The astragalus and calcaneum articulate with the tibia. Also, the distal tarsals articulate with the proximal tarsals.

\section{METATARSALS}

Metatarsals I-IV are complete. They are long, slender and parallel to each other. Metatarsal II is the longest, and the first, third, fourth, fifth become progressively shorter distally, different from the holotype of Sinopterus dongi (Metatarsal I is the longest) (Wang and Zhou 2003), and same as the holotype of Sinopterus atavismus (Lü et al. 2016). Whereas in Sinopterus lingyuanensis (Lü et al. 2016), the metatarsals II and I were the same length. Metatarsals I-IV are very similar in their cross-sectional diameter. Metatarsal IV is about $87.6 \%$ the length of metatarsal I. Metatarsal III is about $26.3 \%, 34.3 \%$ and $22.4 \%$ the length of the wing metacarpal, femur and tibia, respectively. Metatarsal V is hook-shaped, and about $25.6 \%$ the length of metatarsal I.

\section{PEDAL DIGITS}

The pedal digits are well preserved. The phalangeal formula of the pedal digits is "2-3-4-5-1". The phalanges display only a mild curvature along their shaft, same as in Tapejara (Eck et al. 2011). The first phalanx of pedal digit $\mathrm{V}$, the second phalanx of pedal digit III, and second and third phalanges of pedal digit IV are very short. The unguals preserved are strongly curved, about same size as the manus, same as the Sinopterus dongi IVPP V 13363 and Sinopterus lingyuanensis (Wang and Zhou 2003, Lü et al. 2016). While in other Sinopterus, such as the Sinopterus benxiensis and Sinopterus dongi D 2525, the manual unguals are about twice as long as the pedals (Lü et al. 2006b, 2007).

\section{DISCUSSION}

Except for D 2525 which represents an adult individual of Sinopterus (Lü et al. 2006b), all 
Chinese tapejarid pterosaurs known so far were immature individuals at the time of death. Here, we report on a new Sinopterus specimen from the Jiufotang Formation. We have shown that it can be referred to the Tapejaridae by several features, such as well-developed cranial sagittal crests, posterior part of the ossified portion of the sagittal crest low, and a large nasoantorbital fenestra (Kellner 2004, Kellner and Campos 2007, Pêgas et al. 2016). The new material (IVPP V 23388) is assigned to Sinopterus based on the following characters: pointed rostrum; long and low skull; a low and small sagittal crest of premaxilla and dentary; the ratio between the lengths of several postcranial elements (e.g., forelimb/ hind limb; metatarsal III/ tibia) is similar to other specimens of Sinopterus (Table V); strongly curved scapula; and expanded coracoid at the articulation to the scapula (Wang and Zhou 2003).

The holotype of "Huaxiapterus" atavismus (Lü et al. 2016) was based on a small-sized skeleton that differed from the other Chinese tapejarids only by two characteristics: the ventral margins of the second and third phalanges of manual digit IV have a distinct groove structure; and the holotype of "Huaxiapterus" atavismus presents a square "crest". However, these two diagnostic characteristics are invalid. The former is not diagnostic of the species, because Lü et al. (2016) ignored or omitted that the feature is also present in some Azhdarchids (Unwin 2003, Ösi et al. 2005, Vremir et al. 2013), and at least in some other tapejarids (Martill and Naish 2006), they have a T-shaped cross-section of the wing phalanges thus implying two grooves. The latter argument is apparently, a mistaken observation. Based on our current observation, the holotype of "Huaxiapterus" atavismus does not present a square "crest", the "crest" is an uncertain cranial bone but is not part of the premaxilla. Based on this, we conclude that "Huaxiapterus" atavismus should be renamed Sinopterus atavismus.
The new specimen shares some features with the holotype of Sinopterus atavismus. Their skulls preserve a pointed process in the middle part of the dorsal margin of the premaxillary crest (Fig. 6 ), while the premaxillary crest of other Chinese tapejarids is smooth in the same position (e.g., Wang and Zhou 2003, Li et al. 2003, Lü and Yuan 2005, Lü et al. 2016) or present a square morphology (e.g., Lü et al. 2006a, 2007) (Fig. 6). Secondly, the dorsal margin of the premaxilla, from the tip to the middle part of premaxillary crest forms a slant line, whereas it is slightly concave in the other Chinese tapejarids (e.g., Wang and Zhou 2003, Li et al. 2003, Lü and Yuan 2005, Lü et al. 2016) (Fig. 6). Thirdly, their metatarsal II is the longest. The first, third, fourth, and fifth metatarsals become progressively shorter, different from the holotype of Sinopterus dongi (with metatarsal I as the longest) (Wang and Zhou 2003). Although the posterior portion of the skull is not well preserved in the holotype of "Huaxiapterus" atavismus, the elongation trend of the premaxillary crest indicates that the premaxillary crest is short, not as long as that of the new specimen, which may be an ontogenetic signal (Bantim et al. 2015, Pinheiro and Rodrigues 2017).

The proportions between the ulna and humerus in Sinopterus benxiensis are different from other Chinese tapejarids (including the new specimen) (Table V). The ratio between the second wing phalanx and the first wing phalanx is 0.85 in Sinopterus lingyuanensis (Lü et al. 2016), which is higher than that of the new specimen (0.77) (Table $\mathrm{V})$. The ventral edge of the mandibular symphysis bears a low bony crest that extends from the tip of the mandible to a point about two thirds from the posterior end in Sinopterus corollatus (Lü et al. 2006a), while the length of the mandibular symphysis is about three tenths of the total mandibular length in the new specimen.

The new material (IVPP V 23388) provides additional information in our understanding of 
TABLE V

Ratios of the principal postcranial bones of Tapejaridae specimens from the Jiufotang Formation in western Liaoning of China.

\begin{tabular}{|c|c|c|c|c|c|c|c|c|c|}
\hline & $\begin{array}{c}\text { S. dongi } \\
\text { IVPP } \\
\text { V } 13363\end{array}$ & $\begin{array}{l}\text { "S. } \\
\text { gui" }\end{array}$ & $\begin{array}{c}\text { S. dongi } \\
\text { D } 2525\end{array}$ & $\begin{array}{c}S . \\
\text { lingyuanensis }\end{array}$ & $\begin{array}{l}\text { "H. } \\
\text { jiii" }\end{array}$ & $\begin{array}{c}\text { "H". } \\
\text { corollatus }\end{array}$ & $\begin{array}{c}\text { “H”. } \\
\text { benxiensis }\end{array}$ & $\begin{array}{c}\text { “H”. } \\
\text { atavismus }\end{array}$ & $\begin{array}{c}\text { Sinopterus } \\
\text { atavismus } \\
\text { IVPP } \\
\text { V } 23388 \\
\end{array}$ \\
\hline $\begin{array}{l}\text { ph2d4/ } \\
\text { ph1d4 }\end{array}$ & 0.75 & - & 0.73 & 0.85 & 0.78 & 0.65 & 0.74 & 0.79 & 0.77 \\
\hline $\mathrm{mtIII} / \mathrm{ti}$ & 0.2 & - & 0.21 & 0.26 & 0.24 & 0.2 & 0.23 & 0.27 & 0.22 \\
\hline $\begin{array}{l}\text { forelimb/ } \\
\text { hind limb }\end{array}$ & 1.2 & - & 1.2 & 1.1 & 1.2 & 1.2 & 1 & 1.3 & 1.2 \\
\hline $\mathrm{ul} / \mathrm{hu}$ & 1.50 & 1.49 & 1.41 & 1.19 & 1.48 & 1.43 & 1.92 & 1.41 & 1.46 \\
\hline
\end{tabular}

Measurements of Sinopterus dongi IVPP V 13363 from Wang and Zhou (2003), "Sinopters gui” BVP 077 from Li et al. (2003), Sinopterus dongi D 2525 from Lü et al. (2006b), Sinopterus lingyuanensis from Lü et al. (2016), "Huaxiapterus jii” GMN-0311-001 from Lü and Yuan (2005), "Huaxiapterus" corollatus ZMNH M 8131 from Lü et al. (2006a), "Huaxiapterus" benxiensis BXGM V 0011 from Lü et al. (2007), "Huaxiapterus" atavismus from Lü et al. (2016). Abbreviations: S. dongi IVPP V 13363 = Sinopterus dongi IVPP V 13363; "S. gui” = Sinopterus dongi BVP 077 (= "Sinopters gui” BVP 077); S. dongi D $2525=$ Sinopterus dongi D 2525; S. lingyuanensis = Sinopterus lingyuanensis; "H. jii" = Sinopterus dongi GMN-03-11-001 ("Huaxiapterus jii" GMN-03-11-001); “H”. corollatus = Sinopterus corollatus ZMNH M 8131 (“Huaxiapterus" corollatus); "H”. benxiensis = Sinopterus benxiensis BXGM V 0011 ("Huaxiapterus" benxiensis); "H”. atavismus = Sinopterus atavismus ("Huaxiapterus" atavismus); hu- humerus; mtIII- metatarsal III; ph1d4 - first phalanx of manual digit IV; ph2d4 - second phalanx of manual digit IV; ti - tibia; - not preserved.

the postcranial morphology of Chinese tapejarids. First, the midcervicals of the new specimen show a lateral pneumatic foramen, contrasting with the absent condition in other Chinese tapejarids (Lü et al. 2006b, Liu et al. 2014). In fact, among the Brazilian tapejarids (including thalassodromines) (e.g., Kellner 2004, Eck et al. 2011, Elgin and Campos 2012, Aires et al. 2013, Vila Nova et al. 2015, Buchmann et al. 2017), midcervicals also present a lateral pneumatic foramen. Second, the neural spine of the midcervical vertebrae in this specimen is higher than that found in another Chinese tapejarid specimen (PMOL-AP00030) (Liu et al. 2014). Third, the shaft of the humerus is straight, similar to that of most Chinese tapejarids (e.g., Wang and Zhou 2003, Lü and Yuan 2005, Lü et al. 2016), although some Chinese tapejarids present a slightly curved humerus anteriorly (e.g., Lü et al. 2006, Liu et al. 2014). Fourth, no pneumatic foramina are present on the posterior face of the wing metacarpal, between the distal condyles, unlike the condition reported in Tapejara (Eck et al. 2011). Lastly, the diameter of the tibia varies little from the proximal part to the distal end in the new specimen, which is comparable to the condition seen in other Chinese tapejarids (e.g., $S$. dongi, S. benxiensis, the holotype of S. atavismus, S. lingyuanensis), but different from Tapejara (Eck et al. 2011), whose shaft tapers towards the distal end.

By comparing all the ratios of the postcranial elements of Tapejaridae from the Jiufotang Formation in western Liaoning of China (Table V), several ratios change little as they grow older in this genus. For example, ratios of the metatarsal III to tibia and the forelimb (humerus + ulna + wing metacarpal) to the hind limb (femur + tibia + metatarsal III) are uniform.

We conclude that $S$. atavismus does not present a square "crest". The new specimen shares many features with the holotype of $S$. atavismus. The wingspan of the new material is about twice as long as that of the holotype of S. atavismus. Considering that the elongation of the premaxillary crest is different among ontogenetic series of anhanguerid pterosaurs (Bantim et al. 2015, Pinheiro and Rodrigues 2017), there is no character that distinguishes our newly described material, from 
A

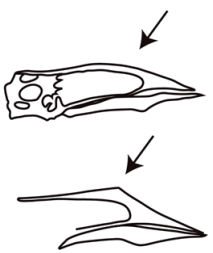

C

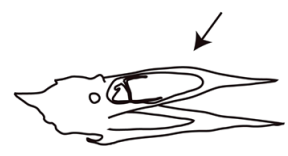

D

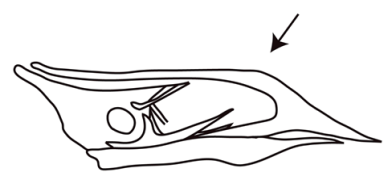

$E$

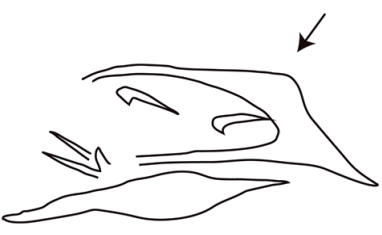

$\mathrm{F}$

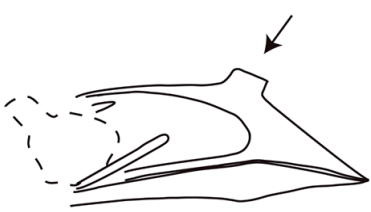

G

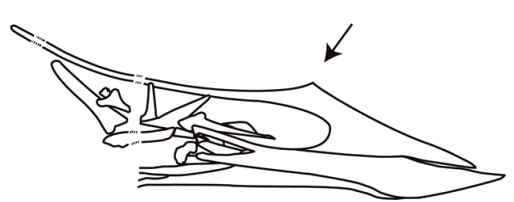

$\mathrm{H}$

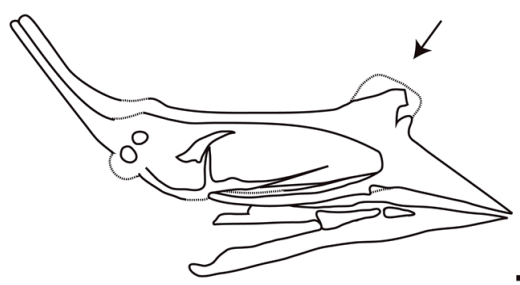

Figure 6 - Cranial morphology of several specimens attributed to Sinopterus. A, Sinopterus dongi BVP 077 ("Sinopters gui" BVP 077) (Li et al. 2003); B, Sinopterus atavismus, XHPM 1009 (Lü et al. 2016); C, Sinopterus lingyuanensis (Lü et al. 2016); D, Sinopterus dongi IVPP V 13363 (Wang and Zhou 2003); E, Sinopterus dongi GMN-03-11-001 ("Huaxiapterus jii" GMN-03-11-001) (Lü and Yuan 2005); F, Sinopterus corollatus ZMNH M 8131 (Lü et al. 2006a); G, Sinopterus atavismus IVPP V 23388; H, Sinopterus benxiensis BXGM V 0011 (Lü et al. 2007). Dashed lines represent reconstructed portions of the cranium. Each arrowhead represents the middle part of the dorsal margin of the premaxillary crest. A, B and $\mathrm{H}$ shown inverted. Scale bars represent $50 \mathrm{~mm}$. the holotype of $S$. atavismus. Therefore, the most parsimonious conclusion is that the new material presented here and $S$. atavismus belong to same species.

\section{ACKNOWLEDGMENTS}

The authors thank all colleagues of our research group, and Alexander W. A. Kellner, Rui Qiu, He Chen, Junxia Wang and Xi Meng for their kind help and comments on this manuscript. We thank Long Xiang for preparing the specimen and Wei Gao for photos. We also thank Paul Rummy, Alida Bailleul (Institute of Vertebrate Paleontology and Paleoanthropology, CAS) and two reviewers for their valuable comments and English correction on the manuscript. This work was supported by the Strategic Priority Research Program (B) of Chinese Academy of Sciences (XDB26000000, XDB18000000), the National Natural Science Foundation of China (41688103, 41602011, 41572020), the State Key Laboratory of Palaeobiology and Stratigraphy (Nanjing Institute of Geology and Palaeontology, CAS) (No. 183113) and the Fundacão Cearense de Apoio ao Desenvolvimento Científico e Tecnológico (FUNCAP) under Grant DCR-0024-02039.01.00/ to Xin Cheng.

\section{AUTHOR CONTRIBUTIONS}

Xinjun Zhang and Xiaolin Wang conceived and designed the experiments, performed the experiments, analyzed the data, wrote the paper, prepared figures and tables, reviewed drafts of the paper. Shunxing Jiang and Xin Cheng analyzed the data, reviewed and modified drafts of the paper.

\section{REFERENCES}

AIRES ASS, KELLNER AWA, MÜLLER RT, SILVA LRD, PACHECO CP AND DIAS-DA-SILVA S. 2013. New postcranial elements of the Thalassodrominae (Pterodactyloidea, Tapejaridae) from the Romualdo 
Formation (Aptian-Albian), Santana Group, Araripe Basin, Brazil. Palaeontology 57: 343-355.

ANDRES B, CLARK J AND XU X. 2014. The earliest pterodactyloid and the origin of the group. Curr Biol 24: 1011-1016.

BANTIM RAM, SARAIVA AAF AND SAYÃO JM. 2015. Skull variation and the shape of the sagittal premaxillary crest in anhanguerid pterosaurs (Pterosauria, Pterodactyloidea) from the Araripe Basin, Northeast Brazil. Hist Biol 27: 656-664.

BENNETT SC. 1993.The ontogeny of Pteranodon and other pterosaurs. Paleobiology 19: 92-106.

BENNETT SC. 2001. The osteology and functional morphology of the Late Cretaceous pterosaur Pteranodon Part I. General description of osteology. Palaeontogr Abt A 260: 1-112.

BUCHMANN R, RODRIGUES T, POLEGARIO S AND KELLNER AWA. 2017. New information on the postcranial skeleton of the Thalassodrominae (Pterosauria, Pterodactyloidea, Tapejaridae). Hist Biol: 1-11.

ECK K, ELGIN RA AND FREY E. 2011. On the osteology of Tapejara wellnhoferi, Kellner 1989 and the first occurrence of a multiple specimen assemblage from the Santana formation, Araripe Basin, Ne-Brazil. Swiss J Palaeontol 130: 277.

ELGIN RA AND CAMPOS HBN. 2012. A new specimen of the azhdarchoid pterosaur Tapejara wellnhoferi. Hist Biol 24: 586-591.

KELLNER AWA. 1989. A new edentate pterosaur of the Lower Cretaceous from the Araripe Basin, Northeastern Brazil. An Acad Bras Cienc 71: 439-446.

KELLNER AWA. 2004. New information on the Tapejaridae (Pterosauria, Pterodactyloidea) and discussion of the relationships of this clade. Ameghiniana 41: 521-534.

KELLNER AWA. 2010. Comments on the Pteranodontidae (Pterosauria, Pterodactyloidea) with the description of two new species. An Acad Bras Cienc 82: 1063-1084.

KELLNER AWA. 2015. Comments on Triassic pterosaurs with discussion about ontogeny and description of new taxa.. An Acad Bras Cienc 87: 669-689.

KELLNER AWA AND CAMPOS DA. 2007. Short note on the ingroup relationships of the Tapejaridae (Pterosauria, Pterodactyloidea). Bol Mus Nac N S Geol Rio de Janeiro 75: 1-14.

KELLNER AWA AND MOODY JM. 2003. Pterosaur (Pteranodontoidea, Pterodactyloidea) scapulocoracoid from the Early Cretaceous of Venezuela. Geol Soc, London, Special Publications 217: 73-77.

KELLNER AWA AND TOMIDA Y. 2000. Description of a new species of Anhangueridae (Pterodactyloidea) with comments on the pterosaur fauna from the Santana Formation (Aptian-Albian), northeastern Brazil. Nat Sci Mus Mon 17: ix-135.
LI JJ, LÜ JC AND ZHANG BK. 2003. A new sinopterid pterosaur from the Mesozoic of Western Liaoning Province, China. Acta Paleontol Sin 42: 442-447.

LIU DX, ZHOU CF, WANG JQ, LI WG AND WEI QW. 2014. New data on the cervical morphology of the Chinese tapejarine. Hist Biol 27: 638-645.

LÜ JC AND YUAN CX. 2005. New tapejarid pterosaur from western Liaoning, China. Acta Geol Sin-Engl 79: 453-458.

LÜ JC, GAO YB, XING LD, LI ZX AND JI Q. 2007. A New Species of Huaxiapterus (Pterosauria: Tapejaridae) from the Early Cretaceous of Western Liaoning, China. Acta Geol Sin-Engl 81: 683-687.

LÜ JC, JIN XS, UNWIN DM, ZHAO LJ, AZUMA Y AND JI Q. 2006a. A new species of Huaxiapterus (Pterosauria: Pterodactyloidea) from the Lower Cretaceous of western Liaoning, China with comments on the system atics of tapejarid pterosaurs. Acta Geol Sin-Engl 80: 315-326.

LÜ JC, LIU JY, WANG XR, GAO CL, MENG QJ AND JI Q. 2006b. New Material of Pterosaur Sinopterus (Reptilia: Pterosauria) from the Early Cretaceous Jiufotang Formation, Western Liaoning, China. Acta Geol Sin-Engl 80: 783-789.

LÜ JC, TENG FF, SUN DY, SHEN CZ, LI GQ, GAO X AND LIU HF. 2016. The toothless pterosaurs from China. Acta Geol Sin 90: 2513-2525.

MARTILL DM AND NAISH D. 2006. Cranial crest development in the azhdarchoid pterosaur Tupuxuara, with review of the genus and tapejarid monophyly. Palaeontology 49: 925-941.

MANZIG PC, KELLNER AWA, WEINSCHÜTZ LC, FRAGOSO CE, VEGA CS, GUIMARÃES GB, GODOY LC, LICCAEDO A, RICETTI J HZ AND DE MOURA AD. 2014. Discovery of a Rare Pterosaur Bone Bed in a Cretaceous Desert with Insights on Ontogeny and Behavior of Flying Reptiles. PLoS ONE 9: e100005.

PÊGAS RV, LEAL ME AND KELLNER AWA. 2016. A Basal Tapejarine (Pterosauria; Pterodactyloidea; Tapejaridae) from the Crato Formation, Early Cretaceous of Brazil. PLoS ONE 11: e0162692.

PINHEIRO FL AND RODRIGUES T. 2017. Anhanguera taxonomy revisited: is our understanding of Santana Group pterosaur diversity biased by poor biological and stratigraphic control?. PeerJ 5: e3285.

PINHEIRO FL, FORTIER DC, SCHULTZ CL, DE ANDRADE JAFG AND BANTIM RAM. 2011. New information on the pterosaur Tupandactylus imperator, with comments on the relationships of Tapejaridae. Acta Palaeontol Pol 56: 567-580.

UNWIN DM. 2003. On the phylogeny and evolutionary history of pterosaurs. Geol Soc, London, Special Publications 217: 139-190.

VILA NOVA BC, SAYÃO JM, LANGER MC AND KELLNER AWA. 2015. Comments on the 
cervical vertebrae of the Tapejaridae (Pterosauria, Pterodactyloidea) with description of new specimens. Hist Biol 27: 771-781.

VREMIR M, KELLNER AWA, NAISH D AND DYKE GJ. 2013. A New Azhdarchid Pterosaur from the Late Cretaceous of the Transylvanian Basin, Romania: Implications for Azhdarchid Diversity and Distribution. PLoS ONE 8: e54268.

WANG XL AND DONG ZM. 2008. Order Pterosauria. In: Li JL, Wu XC and Zhang FC (Eds), The Chinese fossil reptiles and their kin, $2^{\text {nd }}$ ed., Beijing: Sci Press, p. 215234.

WANG XL AND ZHOU ZH. 2003. A new pterosaur (Pterodactyloidea, Tapejaridae) from the Early Cretaceous Jiufotang Formation of western Liaoning, China and its implications for biostratigraphy. Chin Science Bull 48: 1623.

WANG XL AND ZHOU ZH. 2006. Pterosaur assemblages of the Jehol Biota and their implication for the Early Cretaceous pterosaur radiation. Geol J 41: 405-418.
WANG XL, KELLNER AWA, JIANG SX AND CHENG X. 2012. New toothed flying reptile from Asia: close similarities between early Cretaceous pterosaur faunas from China and Brazil. Naturwissenschaften 99: 249-257.

WANG XL ET AL. 2014. Sexually dimorphic tridimensionally preserved pterosaurs and their eggs from China, Curr Biol 24: $1323-1330$.

WELLNHOFER P AND KELLNER AWA. 1991. The Skull of Tapejara Wellnhoferi (Reptilia, Pterosauria) from the Lower Cretaceous Santana Formation of the Araripe Basin, Northeastern Brazil. Mitt Bayer Staatssalg Palaont Hist Geol 31: 89-106.

WITTON MP. 2013. Pterosaurs: Natural History, Evolution, Anatomy. Princeton and Oxford: Princeton University Press, p. 291.

WU XC, LI JL, WANG XL, JIANG SX AND CHENG X. 2017. Palaeovertebrata Sinica. Volume II: Fishes. Fascicle 4 (Serial no. 8): Basal Archosauromorphs, Crocodylomorphs, and Pterosaurs. Beijing: Science Press (in Chinese) 2017: 285. 